\title{
Antimicrobial activity of Acanthephippium bicolor, Lindley
}

\author{
Kala, $\mathbf{S .}^{{ }^{*}}$ and Senthilkumar, $\mathbf{S}^{2}$ \\ ${ }^{1}$ Department of Botany, Seethalakshmi Ramaswami College, Trichirappalli, India. \\ ${ }^{2}$ Department of Biology and Biotechnology, St.Joseph's College, Trichrappalli, India. \\ E-mail: malavikatry@gmail.com
}

Received 20 August 2009; received in revised form 3 November 2009; accepted 20 November 2009

\begin{abstract}
The Kolli hills, a part of Eastern Ghats of India is a treasure of medicinal plants. An attempt is made to gather information about the traditional use of herbs from the local healers. Acanthephippium bicolor Lindley is being used to treat urinary tract infection. Different parts (leaf, bulb and root) are collected in two seasons (summer and winter) and phytochemicals present in them are analyzed. Leaf is found to possess most of the phytochemicals. Hence leaf is selected as study material. Antimicrobial activity of the various solvent extracts (methanol, ethanol, chloroform, acetone, ethyl acetate, benzene and hexane) is screened for both summer and winter samples. Of the 35 organisms studied, Staphylococcus aureus, Streptococcus foecalis, Bacillus cereus, Proteus vulgaris, Proteus mirabilis, Pseudomonas aeruginosa, Klebsiella pneumoniae, Shigella dysenteriae, Escherichia coli, Microsporum audouinii, Microsporum fulvum, Candida albicans and Trichophyton rubrum are found to be sensitive to leaf extracts. The Gram-positive bacteria are found to be more sensitive than Gram-negative bacteria and fungi. The inhibition is found to be more in methanol extract. This proves that the bioactive compounds reside in methanolic extract. When the summer and winter samples are compared for their antimicrobial efficacy, there is no significant difference. This proves that there is no impact of season on antimicrobial activity of this plant. This research proves that Acanthephippium bicolor Lindley would be the best herbal medicine for Urinary Tract Infection and leaves can be used as herbal and scientific medicine throughout the year as there is no seasonal impact.
\end{abstract}

Keywords: Acanthephippium bicolor Lindley, antimicrobial activity, Urinary Tract Infection, methanol extract

\section{INTRODUCTION}

Health is the essence of productive life; the greatest blessing that a man can enjoy on earth; the root cause for prosperity and success and it is not the result of ever increasing expenditure on medical care. Yet disease, decay and death have always co-existed with life. Disease and illness give one no comfort and peace of mind. The study of disease and their treatment must also have been contemporaneous with the dawn of human intellect. Most of the diseases are caused by microorganisms, which are ubiquitous and proliferate in extreme environments. They have harmed human and disrupted societies over the millennia. A look at the out threats of infectious diseases in the past few years gives an idea of the seriousness and instability of the current situation. Antibiotics are potent weapons against many pathogens. Antibiotics are used to destroy or to slow down their growth. But, we are a vulnerable species, and even in these days of vaccines and antimicrobial drugs, infection continues to be a very serious threat to our future. In recent years, multiple drug resistance in human pathogenic microorganisms has developed due to indiscriminate use of commercial antimicrobial drugs commonly used in the treatment of infectious diseases. Antimicrobial drugs currently used in medicinal practices for treating various diseases often causes serious side effects such as immunosuppression of the host and development of resistance in the microorganisms. Medicinal and aromatic plants and their essence are rich in antibacterial compounds, which could be an alternate to combat against bacterial diseases (Samy et al., 1998).

Antibiotics not only develop drug-resistant strain in body but develop narrow spectrum property of antimicrobial activity. They lead to failure to respond in certain infection caused by Gram-negative bacteria and other microorganisms. They also develop nutritional deficiency in body. The continuous development of infectious diseases of antibiotically resistant strains of microbial pathogens such as $S$. pneumoniae (penicillin resistant) and Enterococci (vancomycin resistant) is a growing problem. It is therefore extremely important to discover and develop new antimicrobial compounds (Tally, 1999). Many of the present pharmaceuticals are derived directly or indirectly from higher plants. Plants have always been a major source of medicine for humankind and early botanical references were often guides to the medicinal plants of a particular region. Even today, approximately, one quarter of all pharmaceuticals contains at least one plant derived ingredient.

Medicinal plants have occupied a distinct place in the human life right from the primitive period. They form the backbone of traditional medicine in the last few decades and have been the subject of very intense 
pharmacological studies. These also represent a valuable resources for a variety of chemicals or secondary metabolites of pharmaceutical importance. It has been estimated that out of about 2000 drugs that have been used in curing human ailments in India, only about 200 are of animal origin and a similar number are of mineral origin. The rest, i.e., about 1500 are of plant origin (Srinivasan et al., 2001). The value of ethno-medicine and traditional pharmacology is nowadays gaining its due recognition in modern medicine because the search for new, potential medicinal plant is more successful if the plants are chosen on an ethnomedical basis. It has been estimated that $74 \%$ of the pharmacologically active plant derived components were discovered after the ethnomedical uses of the plants started to be investigated (Farnsworth and Soejarto, 1991; Sheldon et al., 1997). Herbal remedies used in the traditional medicine provide an interesting and still largely unexplored source for the creation and development of potentially new drugs for chemotherapy which might help to overcome the growing problem of resistance and also the toxicity of the currently available commercial antibiotics. The traditional methods especially the use of medicinal plants still play a vital role to cover the basic health needs in the developing countries. Plants are still recognized as the bedrock for modern medicine to treat infectious diseases (Evans et al., 2002). There are many published reports on the effectiveness of traditional herbs against Gram-positive and Gram-negative microorganisms.

Orchids are one of the largest groups of Angiosperms belonging to the family Orchidaceae. They are known for their diversity of habitats, and they occur in diverse habitat conditions of our country. There are about 20,000 species grouped in about 800 genera distributed all over the world except polar region and dry deserts. India is one of the richest orchid habitats with about 2500 species in 167 genera represented in six sub-families, 17 tribes and 30 sub-tribes. Various phytogeographical situation accompanied by the variation in elevation, temperature, rainfall and humidity have contributed to the rich diversity of orchids in India. Orchids have been described as the 'Royal family' and contain their own specialized characters such as intriguing flowers, exciting colours, varied shapes and great diversity of growth habitats would certainly agree that they are rather special plants (Hedge, 1997). In recent years the group has come under renewed focus for two major reasons:

- Many of the beautiful orchids are threatened due to over exploitation.

- The plants have tremendous scope in horticulture and pharmacognosy, but this potential has remained largely untapped in India (Pathak et al., 2001).

In the $17^{\text {th }}$ century, the aesthetic appreciation was for tulips followed by the rose, gladiolus, chrysanthemum and today virtually orchid has become the cynosure all over the world. This unusual aesthetic beauty is quite popular among the professional and amateur orchid lovers in many parts of the world. Contrarily the medicinal value of a vandanous taxon and of some other taxa including the present-day Eulopia dabia (D. Don) Hochr., Flickingeria nodosa (Dall) and Malaxis rheedii SW. are discussed in 'Charaka Samhita', a classic ancient Indian medicinal treatise written by Charaka in Sanskrit, a few thousand years ago. This forms the first record of Indian orchids and their uses in Ayurvedic medicine (Manilal and Sathishkumar, 1986). Yet only in the later part of the $20^{\text {th }}$ century, the medicinal value of orchid has been recognized. Lawler (1987) published an extensive account on ethnobotany of the family Orchidaceae and discussed the role and usage of many species in food, flavouring, confectionary industries, arts and crafts, animal and the veterinary medicines in several continents of the world. The use of several orchid taxa in medical practice was greatly appreciated by Good in his work 'The Family Flora' published in 1845 (Duggal, 1971). In the Ayurvedic system of medicine a group of eight drugs known as ashtavarga is employed in the preparation of a number of rejuvenating formulations and tonics. The correct identity of these drugs has long been debated. The investigations have indicated that important constituents (drugs) of astavarga, namely jivak (Microstylis walliehii), kakoli (Habenaria acuminata) and ridhi varidhi $(H$. intermedia) are orchidaceous in nature (Handa, 1986).

Folk medicine has reported $A$. bicolor Lindley, a terrestrial orchid, to be antiseptic used to treat wounds. Extracts from the leaves is used in treating urinary tract infections. This information was gathered by questioning local healers and knowledgeable villagers of the Kolli Hills, a part of the Eastern Ghats (South India). The information that a plant is used by traditional healers indicates that it is fertile area for scientific study.

\section{MATERIALS AND METHODS}

\section{Collection of plant materials}

The healthy plant materials of $A$. bicolor Lindley (Subfamily: Epidendroideae, Subtribe: Beltiinae) were collected from the Kolli Hills in two different seasons, viz., May 2003 (summer) and November 2003 (winter). It was authenticated in the Rapinat Herbarium, St. Joseph's college, Tiruchirappalli, Tamil Nadu, India with the help of herbarium record (Plate No. 703; RHT 25392; Matthew, 1996).

\section{Location}

The Kolli Hills, one among the hills of the Eastern Ghats, has its geographical position between $11^{\circ} 10^{\prime} 00^{\prime \prime}$ to $11^{\circ} 30^{\prime} 00^{\prime \prime} \mathrm{N}$ and $78^{\circ} 15^{\prime} 00^{\prime \prime}$ to $78^{\circ} 30^{\prime} 0$ belongs to Namakkal district and it is situated in two taluks namely Namakkal and Rasipuram, covering a total area of about $503 \mathrm{sq} . \mathrm{km}$. The altitude is ranging from 200-1415 m about MSL from the foothills. The mean maximum and minimum temperature is $35^{\circ} \mathrm{C}$ and $18^{\circ} \mathrm{C}$ respectively (Harikrishnan, 1977). 


\section{Morphology}

Leaves about 3 , oblong, lanceolate, acuminate with sheathing petiole about $45 \mathrm{~cm}$ long. Inflorescence lateral with 3-4 flowers, 3-4 cm long, sac-shaped, yellow spotted with red, Lip hinged with 3 keels (Matthew, 1996).

\section{Microorganisms studied and culture media}

The following Gram-positive, Gram-negative bacteria, mutant strain and fungi were selected for the present study and were obtained from Genetics lab, School of Biological Sciences, Madurai Kamaraj University, Madurai, Tamil Nadu, India.

\section{Gram-positive bacteria}

1. Staphylococcus aureus MTCC \# 3163

2. Streptococcus agalactiae ATCC \# 13813

3. Streptococcus faecalis MTCC \# 459

4. Streptococcus pyogenes MTCC \# 1927

5. Streptococcus pneumoniae MTCC \#2672

6. Bacillus cereus MTCC \# 1306

7. Corynebacterium diphtheriae ATCC \# 13812

\section{Gram-negative bacteria}

8. Proteus vulgaris MTCC \# 1771

9. Proteus mirabilis MTCC \# 1429

10. Pseudomonas aeruginosa MTCC \# 2474

11. Enterobacter aerogenes MTCC \# 2990

12. Klebsiella pneumoniae MTCC \# 3040

13. Serratia marcescens MTCC \# 2645

14. Salmonella typhi MTCC \# 734

15. Salmonella enteritidis ATCC \# 13076

16. Shigella dysenteriae ATCC \# 29930

17. Bacteroides fragilis DSM \# 1396

18. Escherichia coli MTCC \# 119

19. Escherichia coli mutant Y 1090

20. Escherichia coli mutant HFrc

21. Escherichia coli mutant KL96

22. Escherichia coli mutant $\mathrm{C}_{2} \mathrm{H}_{5} 6$

\section{Fungi}

23. Microsporum audouinii ATCC \# 11395

24. Microsporum fulvum DSM \# 2024

25. Aspergillus niger MTCC \# 2612

26. Aspergillus flavus MTCC \# 2813

27. Aspergillus fumigatus MTCC \# 2584

28. Candida albicans MTCC \# 1637

29. Candida trapicalis MTCC \# 2795

30. Trichophyton rubrum MTCC \# 296

31. Trichophyton mentagrophytes DSM \# 4870

32. Trichophyton verrucosum DSM \# 7380

33. Penicillum claviforme MTCC \# 2002

34. Penicillium commune DSM \# 2211

35. Epidermophyton floccosum ATCC \# 12724
Bacterial strains were maintained in nutrient agar slants ( $\mathrm{HI}$ Media) at $4{ }^{\circ} \mathrm{C}$. Fungal strains were maintained in Potato Dextrose Agar slants (HI Media) at $4{ }^{\circ} \mathrm{C}$.

The leaf, stem and tubers were separated and surface sterilized with $0.1 \% \mathrm{HgCl}_{2}$ for $5 \mathrm{~min}$, washed thrice with sterilized distilled water for 5 min each time. They were then shade dried and powdered. As alkaloids, flavonoids, fixed oils, tannins and phenolic compounds responsible for antimicrobial activity were found to be present only in leaves, leaves alone were selected for further investigation.

The dried, powdered leaves were extracted by hot extraction process using a Soxhlet extraction device with solvents ranging from polar to non-polar (methanol, ethanol, acetone, ethylacetate, benzene, chloroform and hexane) for $72 \mathrm{~h}$ at a temperature not exceeding the boiling point of the solvent. The filtrates were concentrated in vacuum rotary evaporator at $60{ }^{\circ} \mathrm{C}$ in order to reduce the volume. The paste like extracts were stored in labeled screw capped bottles and kept in refrigerator at $40^{\circ} \mathrm{C}$. Each of the extract was individually reconstituted using minimal amounts of the respective solvent prior to use.

\section{Antibacterial activity}

\section{Disc diffusion method}

\section{Principle}

Disc diffusion method provides a simple and reliable test in routine clinical bacteriology in order to find out the effect of a particular substance on a specific bacterium. This method consists of impregnating small circular discs of standard filter paper with given amount of a chosen concentration of substance. The discs are placed on plates of culture medium previously spread with a bacterial inoculum to be tested. After incubation the degree of sensitivity is determined by measuring the inhibition zone produced by the diffusion of the antibiotic substances from the discs into the surrounding medium.

\section{Procedure}

Circular discs of $6 \mathrm{~mm}$ diameter were prepared from Whatman No.1 filter paper and sterilized in an autoclave. Each paper disc was impregnated with $0.2 \mathrm{~mL}$ of test compound (leaf extract) in the respective solvent for overnight and placed on nutrient agar plates seeded with the test bacterium. The plates were incubated at $37^{\circ} \mathrm{C}$ for $24 \mathrm{~h}$. After $24 \mathrm{~h}$ the zone of inhibition around each disc was measured and recorded. Each extract was tested in triplicate to ensure the reliability of the result. Chloramphenicol (30 g/disc) was used as the reference (positive control). A negative control was prepared with only the solvent used for extraction (Rosoanaivo and Ratsimamanga-Urverge, 1993). 


\section{Agar well diffusion method}

It is also known as plate hole diffusion method or cup diffusion method (Kudi et al., 1999).

\section{Principle}

It is an important method for studying the inhibitory effect of any compound (plant extract or antibiotics) on the growth and multiplication of a particular bacterium.

\section{Procedure}

Nutrient agar was used as the culture medium for this assay. The molten agar was dispensed in pre-sterilized Petri dishes (25 mL each) and allowed to cool. These agar plates were homogenously inoculated with the test bacterium previously suspended in tryptose broth $\left(10^{6}\right.$ cells $/ \mathrm{mL}$ ). The plates were allowed to solidify. After solidification, holes/wells of $6 \mathrm{~mm}$ diameter were punched into the agar with the help of flamed cork borer. $0.2 \mathrm{~mL}$ of the plant extract was filled in each hole. The Petri dishes were incubated at $37{ }^{\circ} \mathrm{C}$ for $24 \mathrm{~h}$. After this incubation period, the diameter of the inhibition zone formed around each hole was measured and recorded. Testing was carried out for each bacterium in triplicate. Negative control was prepared using respective solvents used for extraction. Hundred microlitres of Chloramphenicol (300 $\mathrm{g} /$ well) was used as positive control.

\section{Streak plate method}

\section{Principle}

The inhibitory effect of plant extract can be easily rated by this method with an unaided eye. The result of this test was usually rated as strong inhibition where no growth of the bacterium occurs, as partial inhibition where less growth of the bacterium than normal occurs and as no inhibition where full of growth of the bacterium occurs.

\section{Procedure}

Nutrient agar medium was prepared and $8 \mathrm{~mL}$ of molten agar medium and $2 \mathrm{~mL}$ of the plant extract at different concentration viz., $25 \%, 50 \%, 75 \%$ and $100 \%$ were mixed thoroughly and the mixture was poured into sterile Petri dish under aseptic condition. It was cooled at room temperature. After cooling, the bacterial culture was taken ( $24 \mathrm{~h}$ old) and using an inoculation needle, the bacterial culture was applied on the surface of the agar medium in the form of parallel streaks. For each bacterium triplicates were used. The plates were incubated at $37{ }^{\circ} \mathrm{C}$ for $24 \mathrm{~h}$. Control plates without the plant extract were also maintained for reference (Johnson and Case, 1986).

\section{Antifungal assays}

Antifungal activity of the plant extract was determined by the following assays.

\section{Paper disc agar diffusion method}

\section{Principle}

The antimycotic activity of the plant extracts were evaluated by paper disc agar diffusion method. This method consists of impregnating small circular discs of standard filter paper with given amount of a chosen concentration of substance. The discs were placed on plates of culture medium previously spread with the fungal spores (inoculum). After incubation, the degree of sensitivity was determined by measuring the inhibition zone produced by diffusion of the antibiotic substance from the disc into the surrounding medium.

\section{Procedure}

Test plates were prepared with Sabouraud Dextrose agar medium and inoculated on the surface with a spore suspension of $10^{6} \mathrm{CFU} / \mathrm{mL}$. Sterile paper discs (Whatman No.1) of $6 \mathrm{~mm}$ diameter impregnated with the extract were placed over the test plates. Nystatin (Sigma) 30 $\mathrm{g} / \mathrm{disc}$ was used as standard. The plates were incubated at $30{ }^{\circ} \mathrm{C}$ for $48 \mathrm{~h}$. The diameter of growth inhibition zone around each disc was measured after $48 \mathrm{~h}$ (Barry and Thornsberry, 1991).

\section{Agar well diffusion method}

\section{Principle}

The antifungal activity of the plant extract to various fungi was evaluated by agar well diffusion method. The diameter of the inhibition zone is an indicator of the antifungal activity.

\section{Procedure}

Potato dextrose agar was used to culture the fungal organism. The plates were inoculated with $24 \mathrm{~h}$ culture of respective fungi. With the help of a flamed cork borer 6 $\mathrm{mm}$ wells were cut and to each of the well $0.1 \mathrm{~mL}$ of the extract were aseptically added with the help of sterile syringe. The plates were incubated at room temperature. Inhibition was recorded by measuring the diameter of the inhibition zone after $72 \mathrm{~h}$. Nystatin ( $300 \mathrm{~g} /$ well) was used as standard for comparison of antifungal activity (Gobdi and Irobi, 1992). 


\section{Streak plate method}

\section{Procedure}

Eight millilitre of the molten PDA medium and $2 \mathrm{~mL}$ of sterile plant extract at different concentration viz. 25\%, $50 \%, 75 \%$ and $100 \%$ were mixed thoroughly and the mixture was poured into a pre-sterilized Petri dish under aseptic condition. After cooling small streaks of the test fungi were made on the surface of the medium using a sterilized inoculation needle. The plates were incubated at $37^{\circ} \mathrm{C}$ for $24 \mathrm{~h}$. After incubation period, the results were recorded as strong inhibition (if no growth of the test fungi), partial inhibition (if less growth of test fungi than normal) and no inhibition (if full growth of the test fungi). Control plates without the plant extract were also maintained for reference (Orzechowski, 1972).

\section{Comparison with susceptibility test disc}

Commercially available paper containing standard concentration of antibiotics discs (Chloramphenicol for bacteria, Nystatin for fungi) was used as susceptibility test disc for comparing the antimicrobial efficacy of plant extracts.

\section{Antimicrobial efficacy and season}

The leaves collected in the month of November 2003 were also shade dried and powdered and analyzed for phytochemicals. Antimicrobial efficacy was tested with selected organisms to find out whether there was any difference in activity due to seasonal variation.

\section{Antimicrobial activity of the sample collected in summer}

Seven different extracts of $A$. bicolor Lindley leaf was tested against the microorganisms and their potency was assessed by the presence of inhibition zones and zone diameter. All extracts were able to inhibit the growth of one or more of the tested strains to certain extent. Complete absence of measurable inhibitory action was also observed in some of the extracts against few microorganisms.

\section{RESULTS AND DISCUSSION}

\section{Disc diffusion method}

Among the Gram-positive bacteria tested, the highest activity was recorded in $S$. faecalis followed by $S$. aureus and $B$. cereus. Moderate activity was observed in $C$. diphtheriae and $S$. agalactiae. There was no uniform response within or between the bacterial strains of the same species of Streptococcus. As said above, $S$. faecalis was found to be sensitive to all the solvents tested, and the other three species exhibited only minimum zone of inhibition representing their resistance.
Among Gram-negative bacteria maximum inhibition was observed in $P$. vulgaris, E. coli, $P$. mirabilis, $S$. dysenteriae and $P$. aeruginosa. The moderate activity was observed against $E$. aerogenes, $K$. pneumoniaee, $S$. marcescens, S. typhi and $S$. enteritidis. B. fragilis was found to be resistant exhibiting minimum zone of inhibition. The mutant strains were found to be resistant with least inhibition zone. They showed maximum growth in almost all the solvents with inhibition zone which could not be measurable. But E. coli mutant Y1090 was comparatively susceptible showing inhibition zone of around $1 \mathrm{~cm}$ in methanol, ethanol and chloroform extracts.

Of the fungi tested, C. albicans, Microsporum sp. and T. rubrum recorded maximum diameter of inhibition zone representing their susceptibility to plant extracts. Moderate inhibition was noticed against $A$. fumigatus, $C$. trapicalis, $T$. mentagrophytes and E. floccosum while the other fungal strains were found to be resistant with minimum zone of inhibition. Both the species of Penicillium were resistant with reference to all the solvents tested except alcoholic extract where they exhibited the minimum inhibition. Though Aspergillus sp. tested recorded moderate zone of inhibition they showed minimum zone in less polar compounds. Among the fungi C. albicans was highly sensitive showing mean 1.243 and Penicillium species tested were resistant recording mean 0.233 and 0.224 in $P$. claviformis and $P$. commune respectively.

\section{Agar well diffusion method}

The effect of various extracts on the sensitivity of the selected organisms was tested by agar well diffusion method.

Among the Gram-positive bacteria $S$. faecalis was found to be more sensitive showing maximum zone of inhibition in almost all the solvents. $S$. aureus was also equally susceptible. Moderate inhibition was recorded in $B$. cereus and $C$. diphtheriae while the other bacteria were resistant with profuse growth. These results were almost similar as recorded in disc diffusion method.

Of the Gram-negative bacteria studied by agar well diffusion method, $E$. coli recorded maximum inhibition zone proving its sensitivity followed by its mutant strain Y1090. $P$. vulgaris and $S$. dysenteriae showed almost similar sensitivity to all the extracts. $P$. mirabilis, $P$. aeruginosa, $S$. enteritidis and $E$. aerogenes were moderately inhibited whereas the other species showed only negligible zone of inhibition indicating their resistance to plant extracts the mutant strains HFrc, KL96 and $\mathrm{C}_{2} \mathrm{H}_{5} 6$ were resistant with minimum zone of inhibition in alcoholic extracts alone.

Among fungi Microsporum sp., Candida sp. and T. rubrum were found to be sensitive with maximum zone of inhibition. $A$. fumigatus, $T$. mentagrophytes and $E$. flocossum recorded moderate zone while others were found to be resistant. $A$. niger, $T$. verrucosum and Penicillium sp. were resistant in almost all the solvents tested 


\section{Streak plate method}

The antimicrobial activity of the various extracts of leaves of $A$. bicolor Lindley was studied by streak plate method. The results showed that the concentration of leaf extract and the sensitivity of microorganisms were positively correlated. The results were rated by the unaided eye as:

- $\quad$ Strong inhibition (no bacterial growth)

- Partial inhibition (less growth than normal)

- No inhibition (full growth)

Of the Gram-positive bacteria studied $S$. faecalis, $B$. cereus and $S$. aureus were comparatively sensitive being controlled at $50 \%$ concentration partially while the other organisms needed little higher concentration (75\%) for their partial inhibition. In control, the growth of bacteria was found to be excessive. Profuse growth of the bacteria was observed at $25 \%$ concentration also. Partial inhibition was noticed in alcoholic extract at $50 \%$ level in most of the organisms while the non-polar compounds could inhibit the growth in little higher concentration. All the organisms studied are strongly inhibited in methanol, ethanol and chloroform in $100 \%$ concentration of the leaf extract. While acetone, ethyl acetate, benzene and hexane could inhibit few of the organisms only partially even at $100 \%$ concentration.

When compared to Gram-positive bacteria, Gramnegative bacteria were found to be resistant at lower concentration. Both $S$. dysenteriae and $P$. vulgaris responded similarly to the increase in the concentration of leaf extract. They were inhibited partially only at higher concentration viz. $75 \%$ and $100 \%$. At $25 \%$ and $50 \%$ concentration their growth was as in control plates. E. coll which was found to be susceptible exhibiting moderate zone of inhibition in disc diffusion and agar well diffusion method seem to be controlled only at $100 \%$ concentration. At lower concentrations, the growth was almost comparable to the control. The other organisms were also similar to $E$. coli in their response showing partial inhibition only at $100 \%$ concentrations. Grampositive bacteria are found to be more sensitive than Gram-negative bacteria and fungi, to the leaf extracts. They are inhibited strongly in lower concentration of the extract. This may be due to the cell wall composition or morphological constitutions.

Like Gram-negative bacteria fungi also needed a higher concentration of extract for clear inhibition effects. Only partial inhibition was noticed even at $75 \%$ concentration. C. albicans was the only fungi that showed partial inhibition at $50 \%$ concentration proving the anticandidal activity of the extracts.

There are evidences in literature for the effect of seasons on the antimicrobial activity. Antimicrobial activity of the essential oils from Tunisian $P$. tortuosus (Coss.) Maire proved that in November the essential oil was more effective than that of April against the Gram-positive bacteria, E. faecalis and $S$. aureus. In April the essential oil displayed the highest activity against $S$. aureus (Abdel Wahed et al., 2006). Garcia Vallejo et al. (2006) studied a comparative account of the chemical composition of essential oils from Canary Sage Salvia Canaruensis collected at different seasons of the year. They all showed interesting activities towards Gram-positive bacteria regardless of season. So, antimicrobial activities of the samples collected in May (summer) and November (winter) were tested separately and results are compared to find out the effect of seasonal variation on the antimicrobial of the plant substance. The mean difference between the seasons is not so significant.

Of all the solvents methanol is being bestowed with bioactive compounds as it was effective against all the organisms and the zone of also more. Similar results were reported by earlier findings. Ebi and Ofoefule (1997) reported that methanolic extract of $L$. owerrience leaves exhibited antimicrobial properties. While evaluating the antimicrobial activity of the plant extracts obtained using solvents, Panizzi et al. (2002) reported that the methanolic extract of $R$. ulmifolius showed a larger inhibition zone against Gram-positive and Gram-negative bacteria. The methanol soluble fraction of aqueous extract obtained from the dry heads of $C$. diffusa (Asteraceae) demonstrated antimicrobial activity in twelve evaluated microorganisms (Skilar et al., 2005).

Methanolic root and leaf extracts of $T$. kaiserana were effective against most of the tested microbes. Methanolic leaf extract was the only one of all the tested extracts to inhibit the growth of microorganisms (Fyhrquist et al., 2002). Rabanal et al. (2002) reported that the methanol extracts from all the species of Hypericum studied showed a good antimicrobial activity. The methanol extract of $M$. peltatus leaf demonstrated a moderate degree of in vitro antibacterial activity against 147 bacterial and one fungal isolate tested (Chattopadhyay et al., 2002). Masika and Afolayan (2002) reported that the methanolic extracts of $C$. caffrum and $S$. latifolia inhibited the growth of both the Gram-positive and Gram-negative bacteria.

When the organisms were considered $S$. aureus, $S$. faecalis and $B$. cereus exhibited maximum zone of inhibition among Gram-positive bacteria. The sensitivity of Staphylococcus, Streptococcus and Bacillus was also reported in literature. Neto et al. (2002) studied the antibacterial activity of some Peruvian medicinal plants from Callejon de Huaylas. Most of the extracts were active against Staphylococcus and Streptococcus strains. Chattopadhyay et al. (2002) also reported that the leaves of Mallotus peltatus were active against $S$. aureus, $S$. saprophyticus, $S$. faecalis and $B$. subtilis. Karaman et al. (2003) reported that the aqueous and methanol extracts of Juniperus oxycedrus had inhibition effect towards 57 of 178 strains of bacteria including Bacillus sp., S. aureus and $S$. epidermidis testing by disc diffusion method.

Among Gram-negative bacteria $P$. vulgaris, $P$. mirabilis, $P$. aeruginosa, $S$. dysenteriae, $K$. pneumoniaee and $E$. coli were sensitive. The resistance of $K$. pneumoniaee and $P$. aeruginosa to plant extract was also reported by Rabanal et al. (2002) from the leaf extract of Hypericum from the Canary islands by disc diffusion method. Chakraborty and Brantner (1999) reported that the stem bark extract of Holarrhena pubescens was less 
active against $B$. subtilis, $E$. coli and $P$. aeruginosa by disc diffusion method.

Of the fungi $M$. audounii, M. fulvum, C. albicans and T. rubrum were found to be sensitive. Similar results were observed by Cimanga et al. (2002), while testing antifungal activity of essential oils of some aromatic medicinal plants. They reported that the oil exhibited greater activity against $C$. albicans, $C$. tropicalis, $A$. niger, $T$. mentagrophytes and $M$. canis. The same result was observed in the essential oil of Lantana camara leaves against C. albicans (Kasali, 2002). Many plants have been shown to have antifungal properties including Cassia alata (Darah and Osman, 1995), Malva parviflora (Wang et al., 2001). Acanthospimum australe and Calycophyllum multiflorum (Portillo et al., 2001). Various solvent extracts of dried leaves, stem and fresh fruits of Jatropha gossypifolia were tested against $C$. albicans, $A$. terreus and Fusarium oxysporum. It showed bioactivity against all the test fungi (Madhumathi et al., 2000). The Gram-positive bacteria are found to be inhibited more and fungi, in general are resistant compared to Gram-positive bacteria. Sites on bacteria where antibiotics exert their negative influence on the growth include: i) cell wall, ii) protein synthesis, iii) plasma membrane, and iv) RNA synthesis. The resistance of certain bacteria may be due to the presence either of some mechanisms which can degrade the antimicrobial principles or of relatively more resistant sites where these principles act.

The Gram-positive bacteria are found to be more sensitive than Gram-negative bacteria. This can be accounted by the presence of their thick murein layer, which prevents the entry of inhibitors (Martin, 1995). This difference in the resistance may be attributed to the difference in the cell wall composition. Gram-positive bacteria have single layered cell wall with higher amino sugar content, very little lipid and few amino acids whereas the Gram-negative bacteria have two layered cell wall with lesser amount of amino sugar, lipid forming a major constituent and large variety of amino acids (Sinha and Srivastava, 1987). The ways by which bacteria overcome drug action are many and varied, ranging from intrinsic impermeability to the acquired resistance (Green and Wald, 1996; Williams and Sefton, 1999). Many bacteria are naturally resistant to antibiotics due to the permeability barrier afforded by its outer membrane Lipo Poly Saccharide (LPS). Also its tendency to colonize surface in a biofilm form makes the cells impervious to therapeutic concentration of antibiotics (Idose et al., 1968). In classifying the antibacterial activity as Gramnegative or Gram-positive, it would generally be expected a much greater activity against Gram-positive than Gramnegative bacteria (McCutcheon et al., 1992). These differences may be attributed to the fact that the cell wall of Gram-positive bacteria consists of a single layer whereas the Gram-negative cell wall is multilayered structure and quite complex which acts as a barrier to many environmental substances, including antibiotics (Palombo and Semple, 2001; Tortora, 2001).

Gram-negative bacteria have outer phospholipic membrane carrying the structural Lipo Poly Saccharides components. This makes the cell wall impermeable to antimicrobial chemical substances. The Gram-positive bacteria on the other hand are more susceptible because the peptidoglycan constituting the outer layer is not an effective permeability barrier. Therefore, the walls of Gram-negative organisms are more complex than the Gram-positive ones. The walls act as a diffusional barrier making Gram-negative bacteria less susceptible to the antimicrobial agents than are Gram-positive bacteria (Nostro et al., 2000; Hodges, 2002).

The results of this study support to certain degree the traditional medicinal use of the plant and reinforce the concept that the ethno botanical approach of screening plants as potential source is successful. The orchid possesses the bioactive compounds in its leaves, which are more sustainable resource. It could be used without any detrimental effect to the plant. Harvesting of leaves for medicinal purposes is more sustainable compared to harvesting of plant parts such as roots and stems which if over harvested could cause danger to the survival of the plant.

\section{REFERENCES}

Abdel Wahed, A., Hayder, N., Kilani, S., Mohmoud, A., Chibani, J., Hammami, M., Chekir Ghedira, L. and Ghedira, K. (2006). Chemical composition and antimicrobial activity of essential oils from Tunisian Pituranthos tortuosus (Coss) Maire. Flavour and Fragrance Journal 21, 129-133.

Barry, A. and Thornsberry, C. (1991). Susceptibility test and diffusion test procedures. In: Manual of clinical microbiology. Balows, A. and Shadomy, H. J. (eds.). American Society of Microbiology, Washington DC. pp. 1526-1542.

Chakraborty, A. and Brantner, A. H. (1999). Antibacterial steroid alkaloids from the stem bark of Halarrhena pubescens. Journal of Ethnopharmacology 68, 339-344.

Chattopadhyay, D., Arunachalam, G., Mandal, A. B., Sur, T. K., Mandal, S. C. and Battacharya, S. K. (2002). Antimicrobial and anti-inflammatory activity of folklore: Mallotus peltatus leaf extract. Journal of Ethnopharmacology 82, 229-237.

Cimanga, K., Apers, S., De Bryne, T., Miert, S. V., Hermans, M., Totte, J., Pieters, L., Vlietinck, A. J., Kambu, K. and Tona, J. (2002). Chemical composition and antifungal activity of essential oils of some aromatic medicinal plants growing in the Democratic Republic of Congo. Journal of Essential Oil Research 14, 382-387.

Darah, I. and Osman, H. (1995). Antimicrobial activity .of Cassia alata from Malaysia. Journal of Ethnopharmacology 45, 151-156.

Duggal, S. C. (1971). Orchids in human affairs. Quarterly Journal of Crude Drug Research 11, 1727-1733.

Ebi, G. C. and Ofoefule, S. I. (1997). Investigation into folkloric antimicrobial activities of Landolphia owerrience. Phytotherapy Research 11, 149-151. 
Evans, C. E., Banso, A. and Samuel, O. A. (2002). Efficacy of some nupe medicinal plants against Salmonella typhi: An in vitro study. Journal of Ethnopharmacology 80, 21-24.

Farnsworth, N. R. and Soejarto, D. D. (1991). Global importance of medicinal plants. In: Conservation of medicinal plants. Akerele, O., Heywood, V. and Synge, H. (eds.). Cambridge.

Fyhrquist, P., Mwasumbi, L., Haeggstrom, C. A., Vuorela, H., Hiltunen, R. and Vuorrela, P. (2002). Ethnobotanical and antimicrobial investigation on some species of Terminalia and Combretum (Combretaceae) growing in Tanzania. Journal of Ethnopharmacology 79, 169-177.

Garcia Vallejo, M. C., Moujir, J., Burillo, J., Guerra, I. I., Gonzalez, M., Penate, R. D., Andres, L. S., Luis, J. G., Blanco, F. L. and De Galarreta, C. M. R. (2006). Chemical composition and biological activities of the essential oil of Salvia canariensis. Flavour and Fragrance Journal 21, 72-76.

Gobdi, T. A. and Irobi, O. N. (1992). Antibacterial activities of crude extracts of Aspergillus quadrilineatus isolated from Nigerian cereal. African Journal of Pharmacy and Pharmaceutical Sciences 22, 101-106.

Green, H. and Wald, E. R. (1996). Emerging resistance to antibiotics. Impact on respiratory infections in the outpatient setting. Annals of Allergy, Asthma \& Immunology 77, 167-173.

Handa, S. (1986). Researches on Indian orchids. In: Biology, conservation and culture of orchids. Vij, S. P. (ed.). Malhotra Publishing House, New Delhi, pp. 89100.

Harikrishnan, M. (1977). Working plan for the Salem Forest Division. Government of Tamil Nadu, India.

Hedge, S. N. (1997). Orchid Wealth of India. Proceedings of Indian National Science Academy 63, 229-244.

Hodges, N. (2002). Pharmaceutical application of microbiological techniques. In: Pharmaceutas: The science of dosage from design. Aulton, M. E. (ed.). $2^{\text {nd }}$ ed. Harcourt Publishers Ltd., London. pp. 606.

Idose, O., Guthe, T., Willeox, R. and Deweck, R. L. (1968). Nature and extent of Penicillin side reaction with particular reference to fatalities from anaphylactic shock. Bulletin WHO 38, 159-188.

Johnson, Ted R. and Case, C. (1986). Laboratory experiments in microbiology. The Benjamin Cummings Publishing Co. Inc., California. pp. 34-35.

Karaman, I., Sahin, E., Gulluce, M., Ogutcu, H., Sengul, M. and Adiguzel, A. (2003). Antimicrobial activity of aqueous and methanol extracts of Juniperus oxycedrus L. Journal of Ethnopharmacology 85, 231-235.

Kasali, A. A., Kundayo, O., Oyedeji, A. O., Adeniyi, B. A. and Adeolu, E. O. (2002). Antimicrobial activity of the essential oil of Lantana camera L. leaves. Journal of Essential Oil Bearing Plants 5, 108-110.

Kudi, A. C., Umoh, J. U., Eduvie, L. O. and Gefu, J. (1999). Screening of some Nigerian Medicinal Plants from antibacterial activity. Journal of Ethnopharmacology 67, 225-228.

Lawler, L. J. (1987). Ethnobotany of the Orchidaceae. In: Orchid biology. Vol. III. Arditti, J. (ed.). Cornell University Press, Ithaca. pp. 30-124.

Madhumathi, S., Mohan, M. S. S. and Radha, R. (2000). Antimicrobial properties of crude fruit extracts of Jatropha gossypifolia. Journal of Medicinal and Aromatic Plant Sciences 22, 717-720.

Manilal, K. S. and Sathiskumar, C. (1986). Researches on Indian orchids. In: Biology, conservation and culture of orchids. Vij, S. P. (ed.). pp. 1-2.

Martin, G. J. (1995). Ethnobotany: A methods manual. Chapman and Hall, London. pp. 80.

Masika, P. J. and Afolayan, A. J. (2002). Antimicrobial activity of some plants used for the treatment of livestock disease in the Eastern Cape, South Africa. Journal of Ethnopharmacology 83, 129-134.

Matthew, K.M. (1996). Illustrations on the flora of Palani Hills. Rapinat Herbarium, St. Joseph's College (Autonomous), Tiruchirappalli. pp. 703.

McCutcheon, A. R., Ellis, S. M., Hancock, R. E. W., and Towers, G. H. N. (1992). Antibiotic screening of medicinal plants of British Columbian native peoples. Journal of Ethnopharmacology 32, 213-223.

Neto, C. C., Owens, C. W., Langfield, R. D., Comeau, A. B., Onge, J. St., Vaisberg, A. J., and Hammom, G. B. (2002). Antibacterial activity of some Peruvian medicinal plants from the Callejon de Huaylas. Journal of Ethnopharmacology 79, 133-138.

Nostro, A., Germano, M. P., D'Angelo, V., Marina, A. and Cannatelli, M. A. (2000). Extraction methods and bioautography for evaluation of medicinal plant antimicrobial activity. Letters in Applied Microbiology 30, 379-384.

Orzechowski, G. (1972). Antibiotics in hoheren pflanzen pharmazic in unserer zeit,(French) 42-53.

Palombo, E. A. and Semple, S. J. (2001). Antibacterial activity of traditional Australian medicinal plants. Journal of Ethnopharmacology 77, 151-157.

Panizzi, L., Caponi, C., Calalano, S., Cioni, P. L. and Morelli, I. (2002). In vitro antimicrobial activity of extracts and isolated constituents of Rubus ulmifolius. Journal of Ethnopharmacology 79, 165168.

Portillo, A., Vila, R., Freixa, B., Adzet, T. and Canigueral, S. (2001). Antifungal activity of Paraguayan plants used in traditional medicine. Journal of Ethnopharmacology 76, 93-98.

Pathak, P., Sehgal, R. N., Shekhar, N., Sharma, M. and Sood, A. (2001). Orchids: Science and commerce. ISBN. Shiva Offset Press, Dehradun, India, 81, 211271.

Rabanal, R. M., Arias, A., Prado, B. and HernandezPeroz, M., Sanche, C. C. and Mateo, Z. (2002). Antimicrobial studies of three species of Hypericum from the Canary islands. Journal of Ethnopharmacology 81, 287-292.

Rosoanaivo, P. and Ratsimamanga-Urverge, S. (1993). Biological evaluation in plants with reference to 
Malagasy flora. Monograph of the IFS - NAPRECA Workshop on Bioassays. Antananarivo Madagascar, Madagascar, pp. 72-79.

Samy, R. P., Ignacimuthu, G. and Sen, A. (1998). Screening of 34 Indian medicinal plants for antimicrobial properties. Journal of Ethnopharmacology 62, 172-182.

Sheldon, J., Balick, M. J. and Laird, S. A. (1997). Medicinal plants: Can utilization and conservation coexist? The New York Botanical Garden, Bronx, New York, USA.

Sinha, V. and Srivastava, S. (1987). An introduction to bacteria. Vikas Publishers House Pvt. Ltd., New Delhi. pp. 35.

Skilar, M. J., Toribio, M. S. and Oriani, D. S. (2005). Antimicrobial activity of Centaurea diffusa. Fitoterapia 76, 737-739.

Srinivasan, D., Nathan, S., Suresh, T. and Lakshmana Perumalsamy, P. (2001). Antimicrobial activity of certain Indian medicinal plants used in folkloric medicine. Journal of Ethnopharmacology 74, 217220.

Tally, F. (1999). Researchers reveal ways to defeat 'Superbugs'. Drug Discovery Today 4, 395-398.

Tortora, G. J., Funke, B. R. and Case, C. L. (2001). Microbiology: An introduction. Benjamin Cummings, San Francisco. pp. 88.

Wang, X., Bunkers, G. J., Walters, M. R. and Thoma, R. S. (2001). Purification and characterization of three antifungal proteins from cheese weed (Malva parviflora). Biochemical and Biophysical Research Communications. 20, 1224-1228.

Williams, J. D. and Sefton, A. H. (1999). The prevention of antibiotic resistance during treatment. Infection 2, 29-31. 